\title{
РАЗВИТИЕ РЕЗИСТЕНТНОСТИ К ФУНГИЦИДАМ У ФИТОПАТОГЕННЫХ ГРИБОВ И ИХ ХЕМОСЕНСИБИЛИЗАЦИЯ КАК СПОСОБ ПОВЫШЕНИЯ ЗАЩИТНОЙ ЭФФЕКТИВНОСТИ ТРИАЗОЛОВ И СТРОБИЛУРИНОВ \\ (обзор)
}

\section{Л.А. ЩЕРБАКОВА}

Химический метод до сих пор остается наиболее эффективным способом защиты урожая экономически значимых сельскохозяйственных культур и обеспечения его качества. В мировом сельском хозяйстве сейчас используется не менее 150 фунгицидных соединений с различными механизмами действия, а число разработанных на их основе и зарегистрированных продуктов в несколько раз больше. Триазолы и стробилурины относятся к тем фунгицидам, применение которых в 1980-1990-х годах обеспечило прорыв в борьбе с возбудителями наиболее вредоносных болезней (D. Fernández-Ortuco с соавт., 2008). Однако для надежной защиты растений от поражающих их грибов и оомицетов зачастую необходимы многократные обработки фунгицидами, повторяющиеся в течение каждого нового вегетационного сезона, что ухудшает экологическую ситуацию и повышает риск развития резистентности этих фитопатогенов к фунгицидам. Резистентность - наиболее трудно преодолимое последствие фунгицидных обработок (J.A. Lucas с соавт., 2015), которое делает их во многих случаях малоэффективными и экономически неоправданными (K.J. Brent с соавт., 2007; R.P. Oliver, 2014). Попытки борьбы с резистентными формами фитопатогенных грибов и оомицетов посредством увеличения дозировок фунгицидов и кратности обработок бесперспективны, так как вызывают распространение все более и более устойчивых популяций этих патогенов. Доминирующими в современном сельском хозяйстве тенденциями, направленными на его экологизацию, считают сокращение дозировок фунгицидов без снижения эффективности их защитного действия и преодоление резистентности фитопатогенов. В то же время отказ от современных фунгицидов из группы высокого и среднего риска резистентности, в том числе стробилуринов и триазолов, не представляется удачным с практической точки зрения, поскольку они обеспечивают высокоэффективный контроль широкого спектра заболеваний и имеют ряд других преимуществ (А.В. Филиппов с соавт., 2016). Одной из стратегий, способствующих преодолению многих из вышеуказанных противоречий, могла бы стать хемосенсибилизация фитопатогенов, то есть повышение их чувствительности к фунгицидам. Хемосенсибилизация может быть достигнута при сочетании коммерческого фунгицида с нефунгицидным или обладающим незначительной фунгитоксичностью природным соединением (B.C. Campbell c coавт., 2012; V.G. Dzhavakhiya с соавт., 2012). При этом используются концентрации, которые недостаточны для подавления патогена при раздельной обработке агентами, но при их совместном применении достигается синергетический фунгицидный эффект, в том числе значительно превышающий таковой при дозировках фунгицида, к которым нечувствительны резистентные штаммы. Вещества-хемосенсибилизаторы атакуют биохимические и структурные мишени, отличные от тех, на которых нацелено действие фунгицидов, и поэтому не способствуют отбору резистентных форм. В настоящем обзоре перспективность хемосенсибилизации как антирезистентной стратегии усиления защитного эффекта фунгицидов продемонстрирована на примере нескольких экономически значимых фитопатогенных грибов, чувствительность которых к стробилуринам и триазолам может быть многократно усилена при их совместном применении с метаболитами растений и микроорганизмов или с их аналогами. Кроме того, кратко обсуждается проблема развития резистентности фитопатогенных грибов и приемы, препятствующие ее распространению, приведены сведения о типах и основных механизмах резистентности, в частности о тех, которые ответственны за устойчивость к триазолам и стробилуринам, а также представлена информация о механизмах действия некоторых хемосенсибилизаторов.

Ключевые слова: хемосенсибилизация, резистентность к фунгицидам, фитопатогенные грибы, триазолы, стробилурины, антистрессовые пути метаболизма, преодоление резистентности.

В условиях современного интенсивно развивающегося растениеводства стабильность урожаев сельскохозяйственных культур, особенно возделываемых в промышленных масштабах, невозможно обеспечить без проведения мероприятий по борьбе с болезнями. Среди наиболее опасных возбудителей одну из лидирующих позиций занимают фитопатогенные грибы и

* Работа поддержана РНФ (проект № 18-16-00084). 
оомицеты $(1,2)$. В подавляющем большинстве случаев наиболее востребованным способом борьбы с ними, гарантирующим получение высоких урожаев, сохранение сельскохозяйственной продукции и обеспечение ее качества, по-прежнему остается (и еще долго будет оставаться) обработка фунгицидами.

Вместе с тем хорошо известно, что широкомасштабное применение фунгицидов связано серьезными экологическими и медицинскими рисками, а также с возникновением у патогенов резистентности к этим антигрибным агентам. Хотя в системах интегрированной защиты растений, направленных на экологизацию сельскохозяйственного производства, доминирует тенденция сокращения использования фунгицидов, для надежной защиты урожая и контроля многих фитопатогеных грибов и оомицетов часто требуются многократно повторяющиеся в течение каждого сезона фунгицидные обработки. Например, на картофеле в России проводят до 9-11, а в некоторых европейских странах - до 18 опрыскиваний за сезон. Столь интенсивное применение фунгицидов, несмотря на строгие регламенты, разработанные с целью минимизации рисков, повышает пестицидную нагрузку в агробиоценозах, ухудшает экологическую ситуацию и сопровождается развитием резистентности. Накопление в природных популяциях устойчивых форм грибов и оомицетов представляет собой, пожалуй, наиболее трудно преодолимое нежелательное последствие фунгицидных обработок (3), которое делает их во многих случаях малоэффективными и экономически неоправданными $(5,6)$, а иногда приводит к тому, что целые классы фунгицидов изымаются из оборота (7).

Следует подчеркнуть, что феномен резистентности носит общебиологический характер. Устойчивость к фунгицидам - частный случай естественного процесса биологической эволюции организмов, способных адаптироваться к меняющимся условиям внешней среды, что создает проблемы не только для растениеводства. Так, резистентность бактерий и грибов к медицинским препаратам существенно затрудняет лечение больных бактериальными заболеваниями и микозами $(8,9)$. В целом, резистентность патогенных микроорганизмов остается одной из самых острых проблем современности, а снижение риска ее развития у фитопатогенных грибов актуальной задачей сельскохозяйственной науки. В 1994 году был создан международный Комитет по противодействию резистентности к фунгицидам - Fungicide Resistance Action Committee (FRAC, https://www.frac.info/). Комитет контролирует мониторинг резистентных мутаций в популяциях фитопатогенов и координирует разработку антирезистентных технологий защиты, а также дает рекомендации по снижению риска развития резистентности при использовании фунгицидов против патогенов сельскохозяйственных культур, имеющих экономическое значение в разных странах мира. Европейское сообщество EuroBligh (http://agro.au.dk/forskning/internationale-platforme/euroblight/) специально занимается проблемой резистентности возбудителей фитофтороза (Phytophthora infestans) и ранней гнили (Alternaria solani) картофеля. Поскольку картофель - культура повышенного спроса, эта сеть объединяет не только ученых, но и сельхозпроизводителей, которые заинтересованы в получении максимальных урожаев и используют для этого многократные обработки различными фунгицидами. В России проблеме устойчивости к антибиотикам и фунгицидам также уделяют большое внимание. Так, для предупреждения распространения резистентности патогенных организмов, в том числе поражающих растения, разработана и недавно утверждена соответствующая стратегия (Распоряжение Правительства РФ № 2045-р от 25 сентября 2017 года). 
Проблема резистентности фитопатогенных грибов в сельском хозяйстве. В качестве действующих веществ (ДВ) фунгицидов в мировом сельском хозяйстве используется не менее 150 химических соединений с различными механизмами действия (МД), которые сейчас подразделяют на 46 классов. Кроме того, 12 групп мультисайтовых фунгицидов объединены в отдельный класс $(3,4,10)$. Триазолы (класс G1) и стробилурины (класс С3) относятся к тем группам ДВ, коммерциализация которых в 1980-1990-х годах обеспечила прорыв в борьбе с возбудителями наиболее вредоносных болезней растений во многих странах (11).

Триазолы, или DMI-фунгициды, подавляют синтез грибных стери-

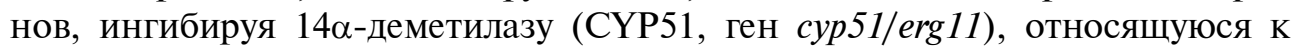
суперсемейству цитохромов Р450. Этот фермент отвечает за отщепление $14 \alpha$-метильной группы ланостерола - предшественника эргостерина (12) (основной стериновый компонент мембран грибов, который отсутствует у растений). Ингибирующее действие этого фермента приводит к дефициту эргостерина и накоплению в клетке гриба токсичных 14- $\alpha$-метилстеринов, высокие концентрации которых усиливают окислительный стресс, вызывают повреждение мембраны и, как следствие, гибель клетки гриба (13). Стробилурины, или QoI-фунгициды, действую как блокаторы убихиноноксидазы (цитохром bc1, CYTB, ген cyt b). Впервые стробилурины А и В обнаружили в культуральной жидкости базидиомицета Strobilurus tenacellus, после чего были получены их химические производные с аналогичным механизмом действия, которые подразделяют на 9 групп $(11,14)$. Стробилурины ингибируют митохондриальное дыхание грибов, связываясь с внешним сайтом цитохрома bcl (комплекса III) и препятствуя передаче электронов между цитохромами b и с. В результате стробилурины подавляют синтез АТФ, вызывая тем самым дефицит энергии в клетках грибов, что приводит к остановке их роста.

На основе различных триазолов и стробилуринов, а также их сочетаний с ДВ из других классов разработано и зарегистрировано большое число фунгицидных продуктов сельскохозяйственного назначения; триазолы также используют в медицине в качестве лекарственных препаратов.

Развитие резистентности к фунгицидам. Вплоть до начала 1970-х годов сообщения о снижении эффективности длительно применявшихся фунгицидов из-за возникновения устойчивых к ним форм фитопатогенов были относительно редки (15). Поэтому казалось, что в сельском хозяйстве проблема резистентности не имеет большого практического значения и может быть решена с помощью баковых смесей, создания новых препаративных форм и тех правил обработки, которые были основаны на опыте применения доминирующих в 1960-е годы групп ДВ (16). Однако с введением новых системных и контактных фунгицидов, особенно с моносайтовым типом активности (включая DMI- и QoI-фунгициды), число случаев снижения или утраты чувствительности и перекрестной резистентности у различных грибов (17-21), в том числе поражающих картофель (22), и оомицетов $(23,24)$ значительно возросло $(4,25)$, а время, необходимое для появления резистентных форм, во многих случаях заметно сократилось иногда до 2 лет после первого коммерческого применения $(11,26,27)$.

Попытки борьбы с резистентными формами посредством увеличения дозировок, норм расхода и кратности обработок новыми фунгицидами, которые вследствие высокой активности против фитопатогенов были рекомендованы к использованию в относительно небольших количествах, лишь обостряли проблему, вызывая накопление все более и более устойчивых штаммов и стимулируя их распространение в популяциях (3). Эта 
тенденция сначала была отмечена практиками, столкнувшимися с падением эффективности химической защиты, а потом доказана экспериментально. В частности, положительную корреляцию между увеличением концентрации триазоловых фунгицидов и накоплением резистентных форм, а также развитием внутригупповой перекрестной резистентности у возбудителя септориоза пшеницы (Zymoseptoria tritici = Mycosphaerella graminicola) подтвердили лабораторные исследования (27). Было показано также, что на фоне повышающихся дозировок и норм расхода азоксистробина к концу вегетационного сезона в популяции возбудителя мучнистой росы ячменя (Blumeria graminis f. sp. hordei) возрастает частота изолятов, устойчивых к этому QoI-фунгициду (28). Аналогичным образом у P. infestans постепенно снижается чувствительность к манкоцебу и хлороталонилу при их многократном использовании, хотя риск развития резистентности к этим мультисайтовым фунгицидам низок (29).

В настоящее время зафиксированы случаи возникновения резистентности почти против всех основных классов фунгицидов у самых разных видов фитопатогенов (10). Триазолы и стробилурины в этом смысле не составляют исключение, и согласно рейтингу FRAC риск резистентности к ним оценивается соответственно как средний и высокий. Как предполагается, быстрое развитие резистентности к QoI-фунгицидам связано с тем, что убихиноноксидаза кодируется митохондриальной ДНК, которая обладает менее выраженной способностью к репарации, чем ядерная ДНК (25). Формы возбудителей альтернариоза картофеля (A. solani и A. alternata), устойчивые к азоксистробину, впервые выявили уже в 2000 году (препараты на его основе начали использовать в конце 1990-х). Внутригрупповая резистентность выявлена у всех ДВ QoI-фунгицидов. У DMI-фунгицидов ее обычно отмечают для тех ДВ, которые активны против одного и того же патогена, и не обнаруживают в отношении ингибиторов синтеза стеринов из других классов.

Основные механизмы резистентности грибов к фунгицидам. Типы резистентности. Молекулярно-биологические исследования изменений генома устойчивых штаммов различных грибов и оомицетов позволили понять механизмы резистентности и показали, что в большинстве случаев она вызвана мутациями генов, кодирующих метаболические мишени фунгицидов, а также связана с различными адаптационными механизмами, запускаемыми химическим стрессом.

В первом случае, типичном для моносайтовых фунгицидов, возникает качественная резистентность (7), которая обычно развивается относительно быстро и с большой вероятностью. При ее распространении в популяциях патогенов накапливаются только полностью устойчивые штаммы, а формы с промежуточной устойчивостью отсутствуют (полная потеря эффективности фунгицида). Однако сохранение форм с резистентностью качественного типа возможно лишь при условии, что мутации генов, кодирующих структурные и метаболические мишени фунгицида, не нарушают жизнеспособности патогена. Так, в популяциях возбудителей окаймляющей пятнистости ржи и ячменя (Rhynchosporium secalis), а также у возбудителей ржавчины злаковых (Puccinia spp.) не удается обнаружить штаммов, устойчивых к QoI-фунгицидам, несмотря на их регулярное применение в течение многих лет. Из-за особой структуры гена цитохрома b у этих грибов типичная для резистентности к стробилуринам мутация G143A вызывает сбой в процессинге мРНК и экспрессию нефункционального белка цитохрома, в результате чего мутанты с аллелем, несущим G143A, не выживают.

Резистентность количественного типа может придавать устойчи- 
вость к фунгицидам с разным механизмом действия и приводить к существованию в популяциях форм с неполной резистентностью (снижение эффективности фунгицида). Она обусловлена несколькими адаптационными механизмами, действие которых направлено на поддержание в клетке нелетальных концентраций фунгицидов. Это достигается за счет усиления экспрессии генов АВС-транспортеров (белки, которые выводят из клетки молекулы лекарственных и других токсичных веществ во внеклеточное пространство; у некоторых фитопатогенов в этом участвуют также MFS-транспортеры), модификации плазматических мембран (снижение проницаемости для фунгицидов), а также синтеза ферментов, которые разрушают фунгицид либо трансформируют его молекулы до нетоксичных для гриба соединений (7, 30-32). Сверхэкспрессия генов, кодирующих биохимические или структурные мишени фунгицидов (33), и использование патогенами альтернативных метаболических путей также могут вносить вклад в обеспечение устойчивости количественного типа $(34,35)$.

Механизмы резистентности к триазолам и стробилуринам. В развитии устойчивости и толерантности к триазолам и стробилуринам у фитопатогенных грибов и оомицетов участвует несколько механизмов, приводящих как к качественной, так и к количественной резистентности. В основном за устойчивость к триазолам ответственны точечные мутации V136A, Y136F, Y137F, A379G, I381V в гене cyp51(erg 11) и его промоторе, а также активация АВС-транспортеров. Например, было показано, что Y136F - точечная мутация в 136-м кодоне, приводящая к замене фенилаланина на тирозин, вызывает развитие резистентности к триадименолу у возбудителей мучнистой росы винограда (Uncinula necator) и ячменя (Erysiphe graminis f. sp. hordei) $(10,36)$. Практически все возможные однонуклеотидные изменения сур 51 были обнаружены у высоко-, слабо и умеренно устойчивых штаммов возбудителя септориоза пшеницы $Z$. tritici (M. graminicola) из Франции и Великобритании, а некоторые штаммы патогена с умеренной или высокой резистентностью содержали вставку в промоторе указанного гена или комбинации точечных мутаций (37). Одновременно было установлено, что устойчивость к DM-ингибиторам у полевых изолятов некоторых фитопатогенных грибов не всегда связана только с аминокислотными заменами в белке CYP51 (12). Так, у мутантных фенотипов Z. tritici (M. graminicola) высокая множественная устойчивость к DMI-фунгицидам, по-видимому, обеспечивается также суперэкспрессией генов белков-транспортеров (37).

Резистентность к стробилуринам обусловлена прежде всего двумя мутациями целевого гена $c y t b$, приводящими к заменам глицина на аланин (G143A) и фенилаланина на лейцин (F129L), а также адаптационными механизмами, в частности сверхэкспрессией альтернативной оксидазы, функционирующей в обход дыхательного комплекса III $(10,12)$. Ни одна из названных мутаций не оказывает отрицательного влияния на жизнеспособность патогенов, поэтому резистентные штаммы с этими точечными заменами часто встречаются в популяциях различных грибов, в том числе патогенов картофеля, риса, ячменя, пшеницы и тыквенных (12). Точечная мутация G143A выявлена у A. alternata, но пока не обнаружена у A. solani (38). Напротив, фенотипы с мутацией F129L известны для обоих видов, вызывающих альтернариоз картофеля. Степень устойчивости таких мутантов A. alternata обычно ниже, чем у фенотипов с G143A, но в американских, канадских и шведских популяциях A. solani отмечен вклад изолятов с F129L в снижение эффективности применения азоксистробина против ранней гнили картофеля $(39,40)$. 
Более детальную информацию можно найти в обзорах $(7,11,12$, $41,42)$, специально посвященных механизмам резистентности, и в экспериментальных статьях, рассматривающих различные мутации, связанные с устойчивостью к DM- (37), Qо-ингибиторам и некоторым другим фунгицидам (43-48), а также роль АВС-транспортеров в процессах их детоксикации $(49,50)$. Здесь же важно отметить, что накопление мутаций в природных популяциях происходит постепенно. К тому же у толерантных или полностью устойчивых к фунгицидам мутантов часто не выявляют ни фенотипических отличий, ни ослабления патогенности или иных дефектов $(45,51)$, поэтому падение эффективности обработок вследствие формирования устойчивости обычно становится заметным после того, как резистентные штаммы начинают доминировать в популяции. Подобным образом на территории картофелеводческих регионов многих стран сформировались популяции P. infestans, полностью устойчивые к фунгицидам группы акриланинов и карбаматов (29).

Антирезистентная стратегия «best practices». Осознание проблемы нарастающего ухудшения биологической и хозяйственной эффективности фунгицидных продуктов привело к разработке стратегии управления резистентностью к фунгицидам (СУР), которая основывается на опыте их наиболее эффективного и рационального практического применения (best practices). СУР представляет собой комплекс правил применения фунгицидов и приемов возделывания обрабатываемых культур, направленный на замедление отбора устойчивых форм патогенов и снижение риска распространения резистентности $(6,52)$. Существенные элементы этой стратегии следующие: во-первых, правильный выбор фунгицидов (если возможно, предпочтение отдается так называемым фунгицидам низкого риска) и их рациональное использование (комбинирование препаратов с моносайтовыми и мультисайтовыми ДВ); во-вторых, обработка фунгицидами с разными механизмами действия, чтобы при развитии устойчивости к одному из них патоген попадал под контроль препарата-партнера с другим МД, а также периодическая ротация препаратов с разными МД. При этом необходимо принимать во внимание запреты на комбинирование или последовательное применение некоторых фунгицидов, регламенты на суммарную дозу и число обработок, строго следовать инструкции по способу применения препарата и не нарушать указанных в ней норм расхода. Кроме того, в СУР большое значение придается выбору устойчивых сортов, севообороту (предшественник не должен способствовать накоплению инфекции) и альтернативным (не химическим) методам защиты растений, а также агротехнике, адекватной району возделывания культуры, чтобы избегать недостаточного или чрезмерного орошения и/или внесения удобрений, поскольку и то, и другое может стимулировать развитие болезней.

Очевидно, что для конкретной комбинации культура-заболевание-географический регион как тактика управления резистентностью в рамках описанной стратегии, так и ее эффективность могут существенно различаться. Например, в Северной Ирландии внедрение СУР в практику картофелеводства привело к сдерживанию отбора штаммов P. infestans, peзистентных к фениламидам (53): их доля в популяциях патогена в 19992001 годах достигала 76 \%, а после внедрения СУР в 2002 году - снизилась через 3 года до $22 \%$ (54). В этом регионе фениламиды успешно используют для борьбы с фитофторозом картофеля, и предполагается, что их применение на фоне антирезистентной технологии будет продолжаться (54). Аналогичным образом в 2004-2005 годах удалось изменить тенденцию по распространению устойчивости к азоксистробину. Однако в ряде реги- 
онов Великобритании и США следование рациональной схеме превентивных или куративных опрыскиваний против альтернариоза и фитофтороза картофеля хотя и позволяло сдерживать развитие болезней на уровне, не приносившим экономического ущерба, но одновременно способствовало отбору штаммов с пониженной чувствительностью к фениламидам у $P$. infestans или к стробилуринам у A. solani (38). Кроме того, выказываются опасения, что даже при соблюдении рекомендаций СУР риск развития резистентности у некоторых грибов и оомицетов, особенно поражающих многолетние растения, может оставаться достаточно высоким (55).

Однако, по мнению FRAC, отказ от современных системных и контактных моносайтовых фунгицидов из групп высокого и среднего риска резистентности, в том числе стробилуринов и триазолов, не представляется удачным с практической точки зрения, поскольку они обеспечивают высокоэффективный контроль широкого спектра заболеваний и имеют ряд других преимуществ (29). Так, стробилурины продолжают сохранять эффективность в отношении возбудителя септориоза пшеницы (Z. tritici) на террирории Италии (56). Результаты исследований 2015 года по проекту EUROwheat (http://agro.au.dk/forskning/internationale-platforme/eurowheat/) также показали, что триазолы, более 35 лет применявшиеся в Северной и Центральной Европе против септориоза колоса (Z. tritici), желтой (P. striiformis) и бурой (P. triticina) ржавчины, успешно защищают пшеницу от этих болезней, в том числе против септориоза, несмотря на обнаружение у его возбудителя шести различных мутаций гена $14 \alpha$-деметилазы и внутригрупповой перекрестной резистентности (57).

В сложившейся ситуации представляется весьма перспективной разработка дополнительных подходов, которые с помощью экологически безопасных соединений позволили бы без увеличения дозировок или числа обработок сохранить или даже усилить защитный эффект современных фунгицидных препаратов и таким образом снизить их селектирующее действие в популяциях фитопатогенов, способствующее отбору резистентных форм. Одним из таких подходов могла бы стать хемосенсибилизация фитопатогенных грибов к сельскохозяйственным фунгицидам.

Хемосенсибилизация как перспективная антирезистентная стратегия повышения эффективности защитного действия фунгицидов. Термин «хемосенсибилизация» заимствован из медицины, где он изначально был введен для обозначения подхода, позволяющего препятствовать развитию резистентности раковых клеток к радиации и химиотерапевтическим противоопухолевым препаратам с помощью хемосенсибилизаторов - химических соединений или природных веществ. При их применении часто наблюдается синергизм, вследствие чего возрастает эффективность лекарств и радиационного воздействия $(8,58)$.

Оказалось, что основные механизмы, определяющие устойчивость клеток опухоли (59), во многом сходны с механизмами резистентности у микроорганизмов, в том числе у грибов, патогенных для человека. В связи с этим хемосенсибилизация стала активно разрабатываться в медицине для преодоления резистентности возбудителей микозов и повышения их чувствительности к антимикотикам с помощью нетоксичных или недостаточно токсичных для полного подавления развития указанных патогенов природных и синтетических соединений (60). Между тем хемосенсибилизационный подход может быть полезен не только для улучшения противогрибковой химиотерапии микозов человека, но и для борьбы с фитопатогенными грибами. Он мог бы стать значимым компонентом антирезистентной стратегии защиты культурных растений с помощью фунгицидов, 
так как способствовал бы ослаблению или преодолению устойчивости к применяемым в настоящее время коммерческим препаратам. Однако пока предпринимаются только единичные попытки распространить аналогичную стратегию в область защиты растений и адаптировать ее для преодоления устойчивости фитопатогенных грибов к коммерческим фунгицидам $(8,61,62)$. Так как при этом принимают во внимание необходимость снижения неблагоприятных экологических последствий, в качестве сенсибилизаторов стараются использовать природные соединения или их деградируемые в окружающей среде аналоги.

Функционирующие как хемосенсибилизаторы природные или синтетические соединения либо нетоксичны для грибов, либо обладают слабой фунгитоксичностью, которая по крайней мере на порядок ниже, чем у ДВ фунгицидов. Весьма эффективными сенсибилизаторами оказываются также потенциально фунгитоксичные вещества (например, такие вторичные метаболиты растений, как тимол или берберин), используемые в минимальных концентрациях, которые оказывают на патоген лишь незначительное ингибирующее (субфунгицидное) действие. Иными словами, при хемосенсибилизации использованные концентрации как фунгицида, так и сенсибилизатора таковы, что в одиночку эти агенты не оказываются достаточно эффективными, но при их совместном применении достигается подавление патогена, в том числе на уровне, значительно превышающем действие тех дозировок фунгицида, к которым нечувствительны резистентные штаммы $(8,61)$. Этот феномен основан на способности хемосенсибилизаторов вызывать различные стрессы, нарушать клеточные структуры или каким-либо иным образом ослаблять фитопатогенные грибы, тем самым повышая их чувствительность к антигрибным препаратам и усиливая эффект последних. Взаимодействие хемосенсибилизаторов с фунгицидами может быть аддитивным, но в большинстве случаев оно носит синергетический характер, что позволяет значительно снизить эффективные концентрации ДВ (иногда на один или даже два порядка) $(8,61)$. Кроме того, ослабляющие патоген изменения метаболизма, вызванные хемосенсибилизаторами, могут привести к тому, что его резистентные формы также станут более чувствительными к фунгициду. Тогда подавление резистентных штаммов и эффективное сдерживание их накопления может быть достигнуто без увеличения рекомендованных дозировок фунгицидных препаратов, что позволит снизить риск отбора резистентных форм и их распространение в популяциях фитопатогенных грибов.

Широкомасштабный скрининг природных соединений, направленный на выявление у них сенсибилизирующей активности для преодоления устойчивости к лекарствам у раковых клеток, бактерий и грибов, привел к обнаружению целевой активности у ряда вторичных метаболитов растений и некоторых микроорганизмов. У растений потенциальные хемосенсибилизаторы найдены среди фенольных кислот, таннинов, терпеноидов (включая моно-, ди- и тритерпены - сапонины), стероидов, алкалоидов, флавоноидов, катехинов, а также в некоторых других группах вторичных метаболитов (63) и их синтетических аналогов $(61,64,65)$. Многие из этих веществ представляют интерес как компоненты лекарств, эффективных против резистентных больничных штаммов возбудителей микозов $(8,66)$. Что касается обитающих в природе грибов, то известна способность коричного альдегида, практически нетоксичного для базидиомицетов, многократно усиливать свою активность против трутовика Laetiporus sulphureus в комбинации с растительными фенолами эвгенолом, кверцитином и катехином $(67,68)$.

Механизмы действия хемосенсибилизаторов, ответственные за уси- 
ление фунгицидного эффекта, не всегда понятны. Тем не менее исследования синергизма природных и синтетических соединений с лекарственными антимикотиками, суммированные в обзоре B.C Campbell c coaвт. (8), показали, что многие из этих соединений влияют на способность грибов реагировать на стресс. Такой стресс может быть вызван как факторами окружающей среды (например, УФ-излучением, засоленностью, засухой и т.п.), так и воздействием фунгитоксичных препаратов. Привлечение к этим исследованиям методов молекулярной генетики позволило обнаружить в системах защиты грибов от стресса звенья, которые могли бы стать биохимическими или структурными мишенями хемосенсибилизаторов. В частности было установлено, что чувствительность патогенных дрожжей и аспергиллов к антимикозным препаратам можно значительно повысить при воздействии соединений, нарушающих защиту этих грибов от окислительного и осмотического стресса (69-71). Было показано также, что добавление в культуры четырех видов ксилотрофных грибов упомянутого выше коричного альдегида, вызывающего осмотический стресс, синергетически усиливает ингибирование роста грибов октилгаллатом - растительным фенолом, который нарушает структуру клеточной мембраны (72) и вызывает апоптоз.

В отличие от медицинских исследований, число работ, в которых метаболиты микробов и растений используют для сенсибилизации фитопатогенных грибов к фунгицидам с целью повышения эффективности последних, в том числе против резистентных штаммов, невелико. Эти эксперименты (73-75) пока не включают обработку растений, зараженных резистентными штаммами, и за исключением двух сообщений $(62,76)$, выполнены при выращивании фитопатогенных грибов в культуре. Тем не менее авторами убедительно доказано наличие синергизма при использовании определенных концентраций этих метаболитов и их синтетических аналогов и подтверждена плодотворность хемосенсибилизационного подхода для повышения фунгицидного эффекта против фитопатогенов.

Первые детальные исследования по сенсибилизации сапротрофных и условно-патогенных для растений грибов вторичными метаболитами растительного происхождения были предприняты сотрудниками одного из научных центров Департамента сельского хозяйства США (United States Department of Agriculture, USDA) в штате Калифорния. Они выполнены на культурах нескольких аспергиллов, которые, будучи факультативными патогенами человека, имеют также сельскохозяйственное значение, и гриба Penicillium expansum, вызывающего гниль плодов яблони. Эти эксперименты показали эффективность 2,3-диоксибензальдегида (2,3-ДОБА), 4-оксибензальдегида (4-ОБА), тимола и 2,5-дигидробензойной кислоты как сенсибилизаторов P. expansum, некоторых видов Aspergillus и токсигенных штаммов A. flavus $(69,77)$. Обнаружено, что применение in vitro 2,3-ДОБА или галловой кислоты совместно со стробилуриновыми фунгицидами крезоксим-метилом и флудиоксонилом приводит к синергетическому повышению их активности против A. flavus и A. parasiticus (78). При использовании в качестве моделей мутантов Saccaromyces cerevisiae с точечными делециями в гене $\operatorname{sod} A$, кодирующем митохондриальную супероксиддисмутазу (Mn-SOD), установлено, что салициловый альдегид, галловая, аскорбиновая и хлорогеновая кислоты делают A. flavus более чувствительным к крезоксим-метилу, так как нарушают функционирование метаболических систем гриба, ответственных за защиту от окислительного стресса, вызванного этим фунгицидом (79). Повышение фунгицидной активности флудиоксонила в отношении $A$. flavus было продемонстрировано для берберина 
(алкалоид барбариса) и некоторых фенольных соединений, также воздействующих на антиоксидазные системы гриба (69). Выяснено, что активность альдегида салициловой кислоты и других бензоаналогов основана на торможении HOG1-сигнальной системы, контролирующей у A. flavus и $P$. expansum защиту от осмотического стресса $(64,70,79)$. Кроме того, на примере койевой кислоты, которую продуцируют многие мицелиальные грибы, показано, что, несмотря на общий механизм действия, некоторые из сенсибилизаторов могут быть видо- и/или штаммоспецифичными $(80,81)$. Наконец, продемонстрировано, что алкилгаллаты способны усиливать чувствительность к флудиоксонилу у резистентных штаммов P. expansum (73).

В целом, в результате исследований, проведенных вышеупомянутой группой американских ученых, достигнуто понимание того, что известные в настоящее время сенсибилизаторы атакуют те пути метаболизма грибов, которые контролируют их защитный ответ на окислительный стресс, а также усиливают его, провоцируя генерацию токсичных для гриба активных форм кислорода, и нарушают целостность клеточной и вакуолярных мембран, вызывая осмотический стресс и апоптоз. Однако значимость этих механизмов продемонстрирована пока для небольшого числа патогенных грибов, и многие аспекты хемосенсибилизации фитопатогенов к сельскохозяйственным фунгицидам остаются неизученными (8).

Благодаря исследованиям последних лет в список грибов, чувствительность которых к стробилуринам и триазолам может быть многократно повышена с помощью хемосенсибилизации природными метаболитами и их аналогами, включены экономически значимые фитопатогены $(61,62$, 74-76). Для некоторых из них перспективность использования этой стратегии с целью повышения защитного эффекта триазолов продемонстрирована на растениях, в том числе в полевых условиях $(62,76)$. Кроме того, показана принципиальная возможность преодоления резистентности природных штаммов возбудителя септориоза колоса пшеницы к этим фунгицидам (75).

Было установлено, что in vitro азоксистробин (Квадрис ${ }^{\circledR}$ КС $25 \%-$ Quadris ${ }^{\circledR}$, «Syngenta AG», Швейцария) в сочетании нефунгитоксичными и нефитотоксичными концентрациями тимола (монотерпеновое фенольное производное одного из ароматических соединений тимьяна) вызывал гораздо более сильное ингибирование роста Bipolaris sorokiniana, Phoma glomerata, A. alternata и Parastagonospora nodorum (= Stagonospora nodorum), чем в случае его индивидуального применения. Эффект дифеноконазола, примененного вместе с тимолом, также значительно усиливался в отношении B. sorokiniana и P. nodorum, причем фунгитоксичность Дивиденда ${ }^{\circledR}$ КЭ 3 \% (дифеноконазол; DIVIDEND ${ }^{\circledR}$, «Syngenta AG», Швейцария) для B. sorokiniana возрастала в 10 раз. Использование тебуконазола с 4-ОБА, 2,3-ДОБА или тимолом сопровождалось усилением ингибирующего эффекта фунгицида в отношении A. alternata. Внесение в среду роста этого гриба только тебуконазола (в виде фунгицида Фоликур ${ }^{\circledR}$ КЭ $25 \%$ - Folicur $^{\circledR}$, «Bayer AG», Германия) или только тимола в концентрациях соответственно 0,5 и 10 ppm приводило к незначительному подавлению роста мицелия, в то время как при их сочетании в тех же концентрациях ингибирование достигало $50 \%$, что почти вдвое превышало ожидаемый суммарный эффект. Такая же тенденция наблюдалась для Fusarium culmorum при комбинировании того же фунгицида с 4-ОБА (61).

Соединения, способные повышать чувствительность фитопатогенных грибов к фунгицидам, обнаружены не только у растений. Примерами использования метаболитов микроорганизмов в качестве сенсибилизаторов могут служить эксперименты, в которых их применяли для повыше- 
ния чувствительности трех патогенов пшеницы (P. nodorum, B. sorokiniana и F. graminearum) к четырем DMI-фунгицидам. Так, недавно мы продемонстрировали возможность сенсибилизации возбудителя обыкновенной корневой гнили и пятнистости листьев злаковых (B. sorokiniana) к тебуконазолу с помощью 6-деметилмевинолина (6-ДММ), который продуцирует P. citrinum. Как и триазолы, 6-ДММ ингибирует биосинтез стеринов, но в отличие от DMI-фунгицидов он действует на 3-окси-3-метилглутарил-CoAредуктазу, ответственную за одну из ранних стадий образования стероидных соединений. В этих экспериментах был определен диапазон сочетаний долевых концентраций Фоликура ${ }^{\circledR}$ КЭ 25 \% и 6-ДММ, которые давали эффект синергизма, свидетельствующий о значительном повышении чувствительности патогена к фунгициду. При совместном применения веществ в наиболее эффективном сочетании долевых концентрациях этого диапазона достигалось полное подавление роста грибных колоний, в то время как сенсибилизатор и фунгицид, отдельно взятые в тех же концентрациях, вызывали только 10-20\% торможение роста (74).

Кроме того, у экзометаболитов непатогенного для пшеницы изолята $F$. sambucinum при их тестировании in vitro совместно с тебуконазолом сначала была выявлена сенсибилизирующая активность в отношении $P$. nodorum, которая выражалась не только в усилении, но и в пролонгировании фунгицидного эффекта (61). Затем эти метаболиты успешно использовали в вегетационных опытах для повышения чувствительности указанного патогена к Фоликуру ${ }^{\circledR}$ БТ КЭ 225 (ДВ - тебуконазол и его производное триадимефон). Результаты последующих полевых испытаний показали, что совместная обработка растений содержащим сенсибилизаторы фильтратом культуральной жидкости (ФКЖ) F. sambucinum и этим фунгицидом позволяет снизить его дозировку по сравнению с рекомендованной в 5 раз без потери защитной активности и фунгицидного эффекта против возбудителя септориоза (76). Поскольку у пшеницы состояние флаг-листа имеет решающее значение для обеспечения урожая, важно, что в опытах с искусственной инокуляцией растений обработка на стадии кущения фунгицидом вместе с ФКЖ лучше защищала флаг-лист в течение всего вегетационного периода, чем обработка только фунгицидом. У растений, которые опрыскивали Фоликуром ${ }^{\circledR}$ БТ КЭ 225 в обычной дозировке, средняя площадь поражения флаговых листьев была в 12-15 меныше, чем у необработанных. Если же дозировка фунгицида составляла пятую часть от нормы, его индивидуальное применение приводило к 5-7-кратному уменьшению средней площади поражения, тогда как после использования той же дозы препарата вместе с ФКЖ этот показатель снижался почти в 40 раз. На основе сенсибилизаторов из $F$. sambucinum разработан композитный препарат, предназначенный для защиты растений (82).

Другими активными сенсибилизаторами микробного происхождения оказались циклические липопептиды (итурин А, фенгицин и сурфактин) одного из штаммов (JCK-12) почвообитающей бактерии Bacillus amyloliquefaciens. Синергизм между содержащим их экстрактом и триазолами (дифеноконазолом и тебуконазолом), а также фунгицидами с другими МД (флудиоксанилом и беномилом) приводил к заметному усилению ингибирования роста колоний $F$. graminearum. Сами липопептиды не проявляли фунгицидной активности вплоть до концентраций 30 ppm, но ингибирующее действие их смесей с фунгицидами на прорастание конидий гриба имело синергетический характер. Тепличные и полевые обработки растений препаратом на основе культурального бульона JCK-12 показали, что его совместное использование с фунгицидом Almuri ${ }^{\circledR}$ (ДВ дифеноконазол 
и пропиконазол; «Syngenta», Корея) может существенно улучшать эффективность защиты пшеницы этим двухкомпонентным препаратом (62). Авторы предполагают, что повышение чувствительности гриба к фунгицидам под влиянием JCK-12 может быть следствием повреждения клеточной стенки и изменения проницаемости клеточной мембраны $F$. graminearum, вызванных смесью бактериальных липопептидов.

Что касается синтетических соединений, то определенная хемосенсибилизирующая активность недавно выявлена нами in vitro у некоторых фосфоаналогов природных аминокислот в тестах с P. glomerata, A. alternata и $F$. culmorum (65). В частности, мы проверили несколько структурных аналогов аминокислот, ингибирующих биосинтез поликетидных микотоксинов, которые у некоторых грибов играют важную роль в патогенности. Хемосенсибилизирующий эффект и синергизм с тебуконазолом (Фоликур ${ }^{\circledR}$ КЭ $25 \%$ ) был выявлен как для нефунгицидных, так и для субфунгицидных концентраций этих соединений. Поскольку структура этих аналогов природных веществ известна и не слишком сложна, ее поэтапная модификация с одновременным определением целевой активности могли бы привести к синтезу относительно недорогих и экологичных препаратов для повышения фунгицидной чувствительности фитопатогенных грибов. Успех этого направления стал бы серьезным подтверждением предположения о перспективности использования синтетических соединений в качестве сенсибилизаторов (8), коммерческий интерес к которым пока сдерживается довольно высокой стоимостью их производства.

Наконец, нам удалось получить новые экспериментальные доказательства эффективности хемосенсибилизаторов природного происхождения против резистентных форм фитопатогенов, а именно против устойчивого к Дивиденду ${ }^{\circledR}$ (3 \% дифеноконазол) природного мутанта P. nodorum, чувствительность которого к этому триазолу удалось увеличить с помощью тимола (75). При культивировании патогена на средах с сублетальной концентрацией дифеноконазола у одной из колоний был выявлен сектор, который рос более интенсивно, чем ее другие участки. Ингибирование роста клона, выделенного из этого сектор, в присутствии фунгицида оказалось почти вдвое слабее, чем у диких изолятов. На средах с возрастающими концентрациями фунгицида был отселектирован устойчивый к Дивиденду ${ }^{\circledR}$ штамм PNm1 и установлено, что его резистентность обусловлена генетической мутацией. Применение фунгицида совместно с тимолом приводило к статистически достоверному снижению устойчивости мутантного штамма до уровня, соответствующего чувствительности нерезистентного родительского изолята, причем ингибирование роста после внесения в среду дифеноконазола совместно с сенсибилизатором достоверно превышало ожидаемый аддитивный эффект этих веществ при раздельном применении (75).

Поводя итог обсуждению резистентности фитопатогенных грибов к фунгицидам, отметим, что в отличие от медицинских антимикотиков, которые должны обеспечить полное уничтожение патогена, средства защиты растений предназначены скорее для того, чтобы как можно дольше задержать развитие популяции возбудителя на уровне ниже порога экономической вредоносности. В этой связи особый интерес переставляет способность некоторых хемосенсибилизаторов пролонгировать фунгицидный эффект (61).

Таким образом, вследствие усиления действия фунгицидов при совместном применении с сенсибилизаторами надежный контроль возбудителей может достигаться при существенном снижении дозировок и расхода препаратов без потери или даже с повышением их фунгицидного эффекта. 
Это позволяет предполагать, что использование хемосенсибилизационного подхода в системах интегрированной защиты растений могло бы сделать защитные мероприятия более экономичными и успешными, в том числе против резистентных форм фитопатогенных грибов. Важных фактором служит доступность многих сенсибилизаторов природного происхождения. Анализ состояния исследований в целом показывает перспективность разработки эффективных, экологически совместимых и биоразлагаемых хемосенсибилизаторов для использования в комбинации с фунгицидами.

\section{ЛИТЕРАТУРА}

1. Moore D., Robson G., Trinci A. Fungi as pathogens of plants. In: 21st Century guidebook to fungi. Cambridge University Press, Cambridge, 2000: 67-391 (doi: 10.1017/CBO9780511977022.015).

2. Филиппов А.В. Фитофтороз картофеля. Защита и карантин растений, 2012, 5: 61-88.

3. Lucas J.A., Hawkins N.J., Fraaije B.A. The evolution of fungicide resistance. Advances in Applied Microbiology, 2015, 90: 29-92 (doi: 10.1016/bs.aambs.2014.09.001).

4. Oliver R.P. A reassessment of the risk of rust fungi developing resistance to fungicides. Pest. Manag. Sci., 2014, 70: 1641-1645 (doi: 10.1002/ps.3767).

5. Steffens J.J., Pell E.J., Tien M. Mechanisms of fungicide resistance in phytopathogenic fungi. Current Opinion in Biotechnology, 1996, 7(3): 348-355 (doi: 10.1016/s0958-1669(96)80043-7).

6. Brent K.J., Hollomon D.W. Fungicide resistance in crop pathogens: how can it be managed? Fungicide Resistance Action Committee, Brussels, 2007.

7. Deising H.B., Reimann S., Pascholati S.F. Mechanisms and significance of fungicide resistance. Brazilian Journal of Microbiology, 2008, 39: 286-295 (doi: 10.1590/S1517-838220080002000017).

8. Campbell B.C., Chan K.L., Kim J.H. Chemosensitization as a means to augment commercial antifungal agents. Frontiers in Microbiology, 2012, 3: 79 (doi: 10.3389/fmicb.2012.00079).

9. Mundaca-Shah C., Ogawa V.A., Nicholson A. The global momentum to counter antimicrobial resistance. In: Combating antimicrobial resistance: a one health approach to a global threat: Proceedings of a Workshop. National Academies of Sciences, Engineering, and Medicine, The National Academies Press, Washington, DC, 2017: 5-12 (doi: 10.17226/24914).

10. FRAC Code List (C)*2019. Режим доступа: https://www.frac.info/docs/default-source/publications/frac-code-list/frac-code-list-2019.pdf. Без даты.

11. Fernández-Ortuco D., Torés J.A., de Vicente A., Pérez-García A. Mechanisms of resistance to QoI fungicides in phytopathogenic fungi. International Microbiology, 2008, 11: 1-9 (doi: 10.2436/20.1501.01.38).

12. Ma Z., Michailides T.J. Advances in understanding molecular mechanisms of fungicide resistance and molecular detection of resistant genotypes inphytopathogenic fungi. Crop Protection, 2005, 24: 853-863 (doi: 10.1016/j.cropro.2005.01.011).

13. Шкель Т.В., Василевская А.В., Гилеп А.А., Черновецкий М.А., Лукьяненко И.Г., Усанов С.А. Молекулярный анализ стерол-14- $\alpha$-деметилаз (сур51) патогенных грибов, вызывающих нозокомиальные инфекции. Труды Белорусского государственного университе$m a, 2013,8(1): 152-158$.

14. Balba H. Review of strobilurin fungicide chemicals. Journal of Environmental Science and Health, Part B, 2007, 42: 441-451 (doi: 10.1080/03601230701316465).

15. Brent K.J. Historical perspectives of fungicide resistance. In: Fungicide resistance in crop protection: risk and management /T.S. Thind (ed.). CABI, Wallingford, UK, 2012: 3-20 (doi: 10.1079/9781845939052.0003).

16. Russell P.E. Fungicide Resistance Action Committee (FRAC). Outlooks on Pest Management, 2006, 17(2): 90-92 (doi: 10.1564/16apr10).

17. Walker A.-S., Auclair C., Gredt M., Leroux P. First occurrence of resistance to strobilurin fungicides in Microdochium nivale and Microdochium majus from French naturally infected wheat grains. Pest Manag. Sci., 2009, 65(8): 906-915 (doi: 10.1002/ps.1772).

18. Bardas G.A., Veloukas T., Koutita O., Karaoglanidis G.S. Multiple resistance of Botrytis cinerea from kiwifruit to SDHIs, QoIs and fungicides of other chemical groups. Pest Manag. Sci., 2010, 66(9): 967-973 (doi: 10.1002/ps.1968).

19. Takagaki M., Kaku K., Watanabe S., Kawai K., Shimizu T., Sawada H., Kumakura K., Nagayama K. Mechanism of resistance to carpropamid in Magnaporthe grisea. Pest Manag. Sci., 2004, 60(9): 921-926 (doi: 10.1002/ps.896).

20. Hauslanden H., Adolf B., Leiminger J. Evidence of strobilurine resistant isolates of $A$. solani and A. alternata in Germany. PPO-Special Report, 2015, 17: 93-100.

21. Cheval P., Siah A., Bomble M., Popper A.D., Reignault P., Halama P. Evolution of QoI resistance of the wheat pathogen Zymoseptoria tritici in Northern France. Crop Protection, 2017, 
92: 131-133 (doi: 10.1016/j.cropro.2016.10.0170261).

22. Edin E., Andersson B. The early blight situation in Sweden - species abundance and strobilurin sensitivity. PPO-Special Report, 2014, 16: 83-84.

23. Davidse L.C., Looijen D., Turkensteen L.J., Wal D. Occurrence of metalaxyl-resistant strains of Phytophthora infestans in Dutch potato fields. Netherlands Journal of Plant Pathology, 1981, 87(2): 65-68 (doi: 10.1007/bf01976658).

24. Taylor R.J., Salas B., Secor G.A., Rivera V., Gudmestad N.C. Sensitivity of North American isolates of Phytophthora erythroseptica and Pythium ultimum to mefenoxam (metalaxyl). Plant Disease, 2002, 86(7): 797-802 (doi: 10.1094/pdis.2002.86.7.797).

25. Gisi U., Sierotzki H., Cook A., McCaffery A. Mechanisms influencing the evolution of resistance to Qo inhibitor fungicides. Pest Manag. Sci., 2002, 58(9): 859-867 (doi: 10.1002/ps.565).

26. Bartlett D.W., Clough J.M., Godwin J.R., Hall A.A., Hamer M., Parr-Dobrzanski B. The strobilurin fungicides. Pest Manag. Sci., 2002, 58(7): 649-662 (doi: 10.1002/ps.520).

27. Mavroeidi V.I., Shaw M.W. Sensitivity distributions and cross-resistance patterns of Mycosphaerella graminicola to fluquinconazole, prochloraz and azoxystrobin over a period of 9 years. Crop Protection, 2005, 24(3): 259-266 (doi: 10.1016/j.cropro.2004.07.014).

28. Hobbelen P.H.F., Paveley N.D., Fraaije B.A., Lucas J.A., van den Bosch F. Derivation and testing of a model to predict selection for fungicide resistance. Plant Pathology, 2011, 60(2): 304-313 (doi: 10.1111/j.1365-3059.2010.02380.x).

29. Филиппов А.В., Кузнецова М.А., Рогожин А.Н. Как сохранить устойчивость картофеля к фунгицидам. Картофель и овощи, 2016, 4: 26-28.

30. Zwiers L.H., Stergiopoulos I., Gielkens M.M., Goodall S.D., de Waard M.A. ABC transporters of the wheat pathogen Mycosphaerella graminicola function as protectants against biotic and xenobiotic toxic compounds. Mol. Gen. Genomics, 2003, 269: 499-507 (doi: 10.1007/s00438-0030855-X).

31. de Waard M.A., Andrade A.C., Hayashi K., Schoonbeek H., Stergiopoulos I., Zwiers L.-H. Impact of fungal drug transporters on fungicide sensitivity, multidrug resistance and virulence. Pest Manag. Sci., 2006, 62(3): 195-207 (doi: 10.1002/ps.1150).

32. Hayashi K., Schoonbeek H.J., de Waard M.A. Bcmfs1, a novel major facilitator superfamily transporter from Botrytis cinerea, provides tolerance towards the natural toxic compounds camptothecin and cercosporin and towards fungicides. Applied and Environmental Microbiology, 2002, 68: 4996-5004 (doi: 10.1128/aem.68.10.4996-5004.2002).

33. Schnabel G., Jones A.L. The 14 $\alpha$-demethylase (CYP51A1) gene is overexpressed in Venturia inaequalis strains resistant to myclobutanil. Phytopathology, 2001, 91: 102-110 (doi: 10.1094/PHYTO.2001.91.1.102).

34. Steinfeld U., Sierotzki H., Parisi S., Poirey S., Gisi U. Sensitivity of mitochondrial respiration to different inhibitors in Venturia inaequalis. Pest Manag. Sci., 2001, 57(9): 787-796 (doi: 10.1002/ps.356).

35. Miguez M., Reeve C., Wood P.M., Hollomon D.W. Alternative oxidase reduces the sensitivity of Mycospherella graminicola to QOI fungicides. Pest Manag. Sci., 2004, 60(1): 3-7 (doi: 10.1002/ps.837).

36. Limpert E. Frequencies of virulence and fungicide resistance in the European barley mildew population in 1985. Journal of Phytopathology, 2008, 119(4): 298-311 (doi: 10.1111/j.14390434.1987.tb04401.x).

37. Leroux P., Walker A.-S. Multiple mechanisms account for resistance to sterol $14 \alpha$-demethylation inhibitors in field isolates of Mycosphaerella graminicola. Pest Manag. Sci., 2011, 67(1): 44-59 (doi: 10.1002/ps.2028).

38. Pasche J.S., Wharam C.M., Gudmestad N.C. Shift in sensitivity of Alternaria solani in response to QoI fungicides. Plant Disease, 2004, 88(2): 181-187 (doi: 10.1094/PDIS.2004.88.2.181).

39. Peters R.D., Drake K.A., Gudmestad N.C., Pasche J.S., Shinners-Carnelley T. First report of reduced sensitivity to a QoI fungicide in isolates of Alternaria solani causing early blight of potato in Canada. Plant Disease, 2008, 92(12): 1707-1707 (doi: 10.1094/PDIS-92-12-1707B).

40. Edin E., Liljeroth E., Andersson B. Long term field sampling in Sweden reveals a shift in occurrence of cytochrome b genotype and amino acid substitution F129L in Alternaria solani, together with a high incidence of the G143A substitution in Alternaria alternata. Eur. J. Plant Pathol., 2019, 155: 1-15 (doi: 10.1007/s10658-019-01798-9).

41. Price C.L., Parker J.E., Warrilow A.G.S., Kelly D.E., Kelly S.L. Azole fungicides - understanding resistance mechanisms in agricultural fungal pathogens. Pest Manag. Sci., 2015, 71(8): 1054-1058 (doi: 10.1002/ps.4029).

42. Torriani S.F.F., Frey R., Buitrago C., Wullschleger J., Waldner M., Kuehn R., Scalliet G., Sierotzki H. Succinate-dehydrogenase inhibitor (SDHI) resistance evolution in plant pathogens. In: Modern fungicides and antifungal compounds, Vol. VIII / H.B. Deising, B. Fraaije, A. Mehl, E.C. Oerke, H. Sierotzki, G. Stammler (eds.). Deutsche Phytomedizinische Gesellschaft, 
Braunschweig, 2017: 89-94.

43. Sierotzki H., Wullschleger J., Gisi U. Point mutation in cytochrome b gene conferring resistance to strobilurin fungicides in Erysiphe graminis f. sp. tritici field isolates. Pesticide Biochemistry and Physiology, 2000, 68: 107-112 (doi: 10.1006/pest.2000.2506).

44. Frey R., Lindenberger N., Brunner P.C., Torriani S.F.F. The evolution of Zymoseptoria tritici sensitivity to triazole fungicides. Abstracts of $19^{\text {th }}$ Int. RHB Symposium on Modern Fungicides and Antifungal Compounds. Friedrichroda, 2019: 88.

45. Chen C., Wang J., Luo Q., Yuan S., Zhou M. Characterization and fitness of carbendazimresistant strains of Fusarium graminearum (wheat scab). Pest Manag. Sci., 2007, 63(12): 12011207 (doi: 10.1002/ps.1449).

46. Pasche J.S., Piche L.M., Gudmestad N.C. Effect of the F129L mutation in Alternaria solani on fungicides affecting mitochondrial respiration. Plant Disease, 2005, 89(3): 269-278 (doi: 10.1094/PD-89-0269).

47. Adolf B., Leiminger J., Hausladen H. The F129L mutation of the cytochrome b gene in German A. solani isolates and its impact on their sensitivity towards QoI fungicides. PPO-Special Report, 2014, 16: 195-196.

48. Leiminger J.H., Adolf B., Hausladen H. Occurrence of the F129L mutation in Alternaria solani populations in Germany in response to QoI application, and its effect on sensitivity. Plant $\mathrm{Pa}$ thology, 2014, 63(3): 640-650 (doi: 10.1111/ppa.12120).

49. Jung G., Sang H., Hulvey J., Chang T., Popko J. Multidrug resistance conferred by xenobiotic detoxification in the ascomycete fungus Sclerotinia. In: Modern fungicides and antifungal compounds, Vol. VIII /H.B. Deising, B. Fraaije, A. Mehl, E.C. Oerke, H. Sierotzki, G. Stammler (eds.). Deutsche Phytomedizinische Gesellschaft, Braunschweig, 2017: 101-106.

50. Marzani A., Swarbrick P., Rossall S. Correlation of the F129L mutation in Pyrenophora teres, the pathogen of net blotch of barley, with the efficacy of QoI fungicides. IOSR Journal of Agriculture and Veterinary Science, 2013, 3(4): 66-72 (doi: 10.9790/2380-0346672).

51. Eisermann I., Gottschling D., Kemen E., Karlovsky P., Deising H.B., Wirsel S.G.R. A single amino acid exchange in the novel transcription factor Azrl governs azole tolerance of Fusarium graminearum. Abstracts of $19^{\text {th }}$ Int. RHB Symposium on Modern Fungicides and Antifungal Compounds. Friedrichroda, 2019: 99.

52. Proactive Fungicide Resistance Avoidance. Pesticide Environmental Stewardship. Режим доступа: https://pesticidestewardship.org/resistance/fungicide-resistance/proactive-fungicide-resistanceavoidance/. Дата обращения: 27.09.2019.

53. Dowley L.J., Griffin D., O'Sullivan E. Two decades of monitoring Irish populations of Phytophthora infestans for phenylamide resistance. Potato Research, 2002, 45: 79-84 (doi: 10.1007/bf02732219).

54. Cooke L.R., Little G. Potato late blight control with fluazinam and the current status of phenylamide resistance in Northern Ireland. PPO-Special Report, 2006, 11: 175-184.

55. Beckerman J.L., Sundin G.W., Rosenberger D.A. Do some IPM concepts contribute to the development of fungicide resistance? Lessons learned from the apple scab pathosystem in the United States. Pest Manag. Sci., 2014, 71(3): 331-342 (doi: 10.1002/ps.3715).

56. Battistini G., Ciriani A., Cavina F., Prodi A., Collina M. Strobilurin sensitivity of Zymoseptoria tritici Italian strains. In: Modern fungicides and antifungal compounds, Vol. VIII /H.B. Deising, B. Fraaije, A. Mehl, E.C. Oerke, H. Sierotzki, G. Stammler (eds.). Deutsche Phytomedizinische Gesellschaft, Braunschweig, 2017: 263-264.

57. Jørgensen L.N., Matzen N., Semaskiene R., Korbas M., Danielewicz J., Glazek M., Maumene C., Rodemann B., Weigand S., Hess M., Blake J., Clark B., Kildea S., Bataille C., Ban R. Azoles have different strengths and perform diversely across Europe. In: Modern fungicides and antifungal compounds, Vol. VIII /H.B. Deising, B. Fraaije, A. Mehl, E.C. Oerke, H. Sierotzki, G. Stammler (eds.). Deutsche Phytomedizinische Gesellschaft, Braunschweig, 2017: 129-134.

58. Hemaiswarya S., Kruthiventi A.K., Doble M. Synergism between natural products and antibiotics against infectious diseases. Phytomedicine, 2008, 15(8): 639-652 (doi: 10.1016/j.phymed.2008.06.008).

59. Shabbits J.A., Hu Y., Mayer L.D. Tumor chemosensitization strategies based on apoptosis manipulations. Molecular Cancer Therapeutics, 2003, 2(8): 805-813.

60. Wagner H., Ulrich-Merzenich G. Synergy research: Approaching a new generation of phytopharmaceuticals. Phytomedicine, 2009, 16(2-3): 97-110 (doi: 10.1016/j.phymed.2008.12.018).

61. Dzhavakhiya V., Shcherbakova L., Semina Y., Zhemchuzhina N., Campbell B. Chemosensitization of plant pathogenic fungi to agricultural fungicides. Frontiers in Microbiology, 2012, 3: 87 (doi: 10.3389/fmicb.2012.00087).

62. Kim K., Lee Y., Ha A., Kim J.-I., Park A.R., Yu N.H., Son H., Choi G.J., Park H.W., Lee C.W., Lee T., Lee Y.-W., Kim J.-C. Chemosensitization of Fusarium graminearum to chemical fungicides using cyclic lipopeptides produced by Bacillus amyloliquefaciens strain JCK12. Frontiers in Plant Science, 2017, 8: 2010 (doi: 10.3389/fpls.2017.02010). 
63. Wink M. Evolutionary advantage and molecular modes of action of multicomponent mixtures used in phytomedicine. Current Drug Metabolism, 2008, 9(1)0: 996-1009 (doi: 10.2174/138920008786927794).

64. Kim J.H., Mahoney N., Chan K., Molyneux R.J., May G.S., Campbell B.C. Chemosensitization of fungal pathogens to antimicrobial agents using benzo analogs. FEMS Microbiology Letters, 2008, 281(1): 64-72 (doi: 10.1111/j.1574-6968.2008.01072.x).

65. Dzhavakhiya V.G., Voinova T.M., Statsyuk N.V., Shcherbakova L.A. Sensitization of plant pathogenic fungi to the tebuconazole-based commercial fungicide using some analogues of natural amino acids. AIP Conference Proceedings, 2019, 2063(1): 030005 (doi: 10.1063/1.5087313).

66. Kim J., Campbell B., Mahoney N., Chan K., Molyneux R., May G. Chemosensitization prevents tolerance of Aspergillus fumigatus to antimycotic drugs. Biochemical and Biophysical Research Communications, 2008, 372(1): 266-271 (doi: 10.1016/j.bbrc.2008.05.030).

67. Bang K.H., Lee D.W., Park H.M., Rhee Y.H. Inhibition of fungal cell wall synthesizing enzymes by trans-cinnamaldehyde. Bioscience, Biotechnology, and Biochemistry, 2000, 64(5): 10611063 (doi: 10.1271/bbb.64.1061).

68. Yen T.B., Chang S.T. Synergistic effects of cinnamaldehyde in combination with eugenol against wood decay fungi. Bioresource Technology, 2008, 99(1): 232-236 (doi: 10.1016/j.biortech.2006.11.022).

69. Kim J.H., Campbell B.C., Mahoney N., Chan K.L., Molyneux R.J., May G.S. Enhanced activity of strobilurin and fludioxonil by using berberine and phenolic compounds to target fungal antioxidative stress response. Letters in Applied Microbiology, 2007, 45(2): 134-141 (doi: 10.1111/j.1472-765x.2007.02159.x).

70. Kim J.H., Campbell B.C., Mahoney N., Chan K.L., Molyneux R.J., May G.S. Enhancement of fludioxonil fungicidal activity by disrupting cellular glutathione homeostasis with 2,5dihydroxybenzoic acid. FEMS Microbiology Letters, 2007, 270(2): 284-290 (doi: 10.1111/j.15746968.2007.00682.x).

71. Eschenauer G., Depestel D.D., Carver P.L. Comparison of echinocandin antifungals. Therapeutics and Clinical Risk Management, 2007, 3(1): 71-97 (doi: 10.2147/tcrm.2007.3.1.71).

72. Hsu F.L., Chang H.T., Chang S.T. Evaluation of antifungal properties of octyl gallate and its synergy with cinnamaldehyde. Bioresource Technology, 2007, 98(4): 734-738 (doi: 10.1016/j.biortech.2006.04.002).

73. Kim J.H., Campbell B.C., Mahoney N., Chan K.L., Molyneux R.J., Xiao C.L. Use of chemosensitization to overcome fludioxonil resistance in Penicillium expansum. Letters in Applied Microbiology, 2010, 51(2): 177-183 (doi: 10.1111/j.1472-765x.2010.02875.x).

74. Kartashov M.I., Shcherbakova L.A., Dzhavakhiya V.G. In vitro enhancement of the sensitivity to tebuconazole in Bipolaris sorokiniana, a causative agent of cereal root rots, by a microbial metabolite 6-demethylmevinolin. Abstracts of $19^{\text {th }}$ Int. RHB Symposium on Modern Fungicides and Antifungal Compounds. Friedrichroda, 2019: 48.

75. Kartashov M.I., Shcherbakova L.A., Statsyuk N.V., Dzhavakhiya V.G. Co-application of difenoconazole with thymol results in suppression of a Parastagonospora nodorum mutant strain resistant to this triazole. Advances in Engineering Research, 2019, 183: 1-5.

76. Shcherbakova L.A., Syomina Yu.V., Arslanova L.R., Nazarova T.A., Dzhavakhiya V.G. Metabolites secreted by a nonpathogenic Fusarium sambucinum inhabiting wheat rhizosphere enhance fungicidal effect of some triazoles against Parastagonospora nodorum. AIP Conference Proceedings, 2019, 2063(1): 030018 (doi: org/10.1063/1.5087326).

77. Faria N.C.G., Kim J.H., Goncalves L., Martins M., Chan K.L., Campbell B.C. Enhanced activity of antifungal drugs using natural phenolics against yeast strains of Candida and Cryptococcus. Letters in Applied Microbiology, 2011, 52(5): 506-513 (doi: 10.1111/j.1472-765x.2011.03032.x).

78. Kim J.H., Mahoney N., Chan K.L., Campbell B.C., Haff R.P., Stanker L.H. Use of benzo analogs to enhance antimycotic activity of kresoxim methyl for control of aflatoxigenic fungal pathogens. Frontiers in Microbiology, 2014, 5: 87 (doi: 10.3389/fmicb.2014.00087).

79. Kim J.H., Campbell B.C., Mahoney N., Chan K.L., Molyneux R.J. Chemosensitization of aflatoxigenic fungi to antimycin A and strobilurin using salicylaldehyde, a volatile natural compound targeting cellular antioxidation system. Mycopathologia, 2011, 171: 291-298 (doi: 10.1007/s11046-010-9356-8).

80. Kim J.H., Chang P.K., Chan K.L., Faria N.C.G., Mahoney N., Kim Y.K., Martins M.de L., Campbell B.C. Enhancement of commercial antifungal agents by kojic acid. Int. J. Mol. Sci., 2012, 13(11): 13867-13880 (doi: 10.3390/ijms131113867).

81. Kim J.H., Chan K.L. Augmenting the antifungal activity of an oxidizing agent with kojic acid: control of Penicillium strains infecting crops. Molecules, 2014, 19: 18448-18464 (doi: 10.3390/molecules191118448).

82. Джавахия В.Г., Кэмпбэл Б.К., Шербакова Л.А., Арсланова Л.Р., Жемчужина Н.С., Дроздова Е.И., Сёмина Ю.В. Композитный препарат фунгицидного действия для защиты растений от патогенов, в том числе резистентных к коммерческим фунгицидам. ГНУ ВНИИФ 
Россельхозакадемии (РФ). Патент № RU 2548191 C1. Заявл. 24.12.2013. Опубл. 20.04.2015. Бюл. № 11.

ФГБНУ Всероссийский НИИ фитопатологии,

143050 Россия, Московская обл., Одинцовский р-н, пос. Большие Вяземы, ул. Институт, вл. 5,

\title{
FUNGICIDE RESISTANCE OF PLANT PATHOGENIC FUNGI AND THEIR CHEMOSENSITIZATION AS A TOOL TO INCREASE ANTI-DISEASE EFFECTS OF TRIAZOLES AND STROBILURINES (review)
}

\section{L.A. Shcherbakova}

\author{
All-Russian Research Institute of Phytopathology, 5, ul. Institut, pos. Bol'shie Vyazemy, Odintsovskii Region, Mos- \\ cow Province, 143050 Russia, e-mail larisavniif@yahoo.com \\ ORCID: \\ Shcherbakova L.A. orcid.org/0000-0003-0254-379X \\ The author declares no conflict of interests \\ Acknowledgements: \\ Supported financially by Russian Scientific Foundation (project No. 18-16-00084) \\ Received December 14, 2018 \\ doi: 10.15389 /agrobiology.2019.5.875eng
}

\section{Abstract}

The chemical method for plant protection is still the most reliable way to provide the high yield of economically significant crops and ensure its quality. In the world agriculture, at least 150 different fungicidal compounds with different mechanisms of action are now used, and the number of products developed and registered on their basis is much more. Triazoles and strobilurins belong to fungicides, which have expanded the opportunities to control causative agents of the most damaging diseases (D. Fernández-Ortuco et al., 2008). Nevertheless, multiple applications of fungicides during each new growing season are often required to achieve an effective control of fungal and oomycete pathogens. Such extensive applications of fungicides exacerbate negative impact on environment, and promote developing the resistance by these pathogens, representing the most disturbing consequence of fungicidal treatments (J.A. Lucas et al., 2015) that makes them relatively short-lived and eventually uneconomical (K.J. Brent et al., 2007; R.P. Oliver, 2014). Attempts to combat resistant forms of plant pathogenic fungi and oomycetes by increasing the dosage of fungicides and treatment numbers are futile, as they cause accumulation of more and more resistant strains in fungal populations. Therefore, control of these pathogens by minimal effective dosages of fungicides, without any decrease in the fungicidal efficacy, and search for ways to overcome the plant pathogen resistance to fungicides are dominant trends in plant protection for current sustainable agriculture. At the same time, the rejection of modern fungicides with high and medium risk of the resistance, including strobilurins and triazoles, does not seem to be practically rational, since they provide a highly effective control of a wide range of diseases and have several other advantages (A.V. Filippov et al., 2016). Chemosensitization of plant pathogens by natural compounds to increase efficacy of fungicidal treatments is an approach to solving the aforementioned problems. Chemosensitization can be accomplished by combining a commercial fungicide with a certain non- or marginally fungicidal substance at concentrations where, alone, neither compounds would be effective, while after their co-application a synergistic fungicidal effect is achieved, sometimes at a level significantly exceeding that of the fungicide dosages to which resistant strains are insensitive (B.C. Campbell et al., 2012; V.G. Dzhavakhiya et al., 2012). Since biochemical and structural targets of chemosensitizing substances differ from those targeted by fungicides, chemosensitization do not contribute to the selection of resistant pathogenic form, and reduces the toxic impact on the environment by lowering effective dosage levels of toxic fungicides. In this review, the promise of chemosensitization as an antiresistant strategy to improve efficacy of the protective fungicide effect is exemplified by experiments with several economically significant phytopathogenic fungi, which sensitivity to strobilurins and triazoles was demonstrated to enhance significantly by co-application of these fungicides with secondary plant or microbial metabolites and their synthetic analogues. In addition, the problem of the development of resistance in plant pathogenic fungi and the methods for its management are briefly described, information on the types and main mechanisms of resistance, in particular, those responsible for resistance to triazoles and strobilurins as well as data on the mechanisms of action of some chemosensitizers are presented.

Keywords: chemosensitization, plant pathogenic fungi, resistance to fungicides, triazoles, strobilurins, fungicide stress-responsive metabolic pathways, resistance overcoming. 